\title{
The Effect of Chronic Glucocorticoid Exposure on Brown Adipose Tissue in Cushing's Disease
}

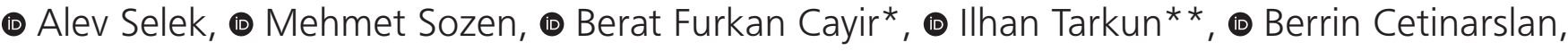 \\ ๑ Zeynep Canturk, ๑ Emre Gezer, ๑ Damla Koksalan
}

Kocaeli University Faculty of Medicine, Department of Endocrinology and Metabolic Diseases, Kocaeli, Turkey

*Ozalp State Hospital, Clinic of Internal Medicine, Van, Turkey

**Anadolu Medical Center, Endocrinology and Metabolic Diseases, Kocaeli, Turkey

Abstract

\begin{abstract}
Aim: In this study, we aimed to evaluate the levels of brown adipose tissue markers uncoupling protein-1 (UCP-1), irisin, bone morphogenetic protein-7 (BMP-7) and PR-Domain Zinc Finger Protein-16 (PRDM-16) in Cushing's disease (CH) with hypercortisolism.

Methods: The study was conducted prospectively with $48 \mathrm{CH}$ patients and 40 healthy volunteers between 2018 and 2019 . Two cc of peripheral blood taken from the participants was centrifuged and stored at $-80{ }^{\circ} \mathrm{C}$ degrees. Cushing's syndrome was excluded by performing $1 \mathrm{mg}$ dexamethasone suppression test in the control group. Blood samples were analyzed by Enzyme-linked Immunosorbent Assay method.
\end{abstract}

Results: The patient group included 11 males (22.9\%), 37 female (77.1\%); 9 male (22.5\%) and 31 females (77.5\%) in the control group. Body mass index was $31.29 \pm 5.76 \mathrm{~kg} / \mathrm{m}^{2}$ in the patient group and $33.42 \pm 3.11 \mathrm{~kg} / \mathrm{m}^{2}$ in the control group. PRDM-16, Irisin, BMP7, UCP-1 levels were not significantly different between the two groups. While there was a positive correlation between serum cortisol and irisin, a negative correlation was observed between urinary free cortisol and UCP-1.

Conclusion: These data suggest that long-term exposure to high doses of glucocorticoids in $\mathrm{CH}$ patients causes loss of adipose tissue functionality and development of resistance in vivo.

Keywords: Cushing's disease, glucocorticoid, brown fat tissue, UCP-1, irisin, BMP-7, PRDM-16

\section{Introduction}

Cushing syndrome (CS) results from long-lasting and inappropriate exposure to excessive concentrations of free glucocorticoids in the bloodstream. It leads to many comorbid conditions including chronic hypercortisolism, obesity, hypertension, diabetes, dyslipidemia and cerebrovascular diseases (1). Adipose tissue plays a central role in the interaction between nutrition, energy balance and human health. White adipose tissue (WAT) stores the energy, whereas brown adipose tissue (BAT) distributes the energy. With the discovery of BAT that has a high metabolic activity by functional imaging methods, research on importance of BAT has been increasing (2). Uncoupling protein-1 (UCP-1) is localized in the inner membrane of mitochondria of BAT cells and leads to a very high amount of fatty acid oxidation that directly produces heat through annihilation of the negative feedback inhibition on the mitochondrial Krebs cycle executed by high adenosine triphosphate and/or low adenosine diphosphate levels (3). In studies, several mediators which regulates UCP1 expression and are involved in differentiation of BAT, including irisin, bone morphogenetic protein-7 (BMP-7) and PR-Domain Zinc Finger Protein-16 (PRDM-16), have been described (4-6).

Knowledge on effect of glucocorticoids on functions of BAT in humans is insufficient. Glucocorticoids have

Address for Correspondence/Yazışma Adresi: Mehmet Sozen, Kocaeli University Faculty of Medicine, 
been shown to inhibit the reaction of adipocytes in human BAT cultures to adrenergic stimulation in vitro (7). While glucocorticoids alter the brown preadipocyte tissue, it suppresses UCP-1 expression and activity in brown adipocytes. In animal trials, lipid deposition in BAT increases with the administration of glucocorticoids, whereas thermogenic activity and production of UCP-1 are decreased (8).

In our study, it was aimed to evaluated levels of UCP1, irisin, BMP-7 and PRDM-16, which are considered as markers for brown adipose tissue, in Cushing's disease $(\mathrm{CH})$ cases with hypercortisolemia.

\section{Methods}

This study was approved by Kocaeli University Ethics Committee on Noninvasive Clinical Research with the project number KU GOKAEK 2018/274 on 27.10.2018. For the clinical prospective study in which the levels of UCP-1, irisin, BMP-7 and PRDM-16, which are considered as markers for brown adipose tissue, were evaluated in $\mathrm{CH}$ cases, 48 patients diagnosed with $\mathrm{CH}$ who were being followed-up between 15.11.2018 and 01.04.2019 in Kocaeli University Department of Endocrinology and Metabolism. As a control group, 40 volunteers at 30-60 years of age who were overweight or obese, screened for $\mathrm{CH}$ and found to be negative, had normal glucose tolerance and had not used any hormone therapy for last 6 months were recruited. Data of those with $\mathrm{CH}$ and volunteers were obtained from the hospitals' automation system and patients' files.

Those who were on an insulin or incretin-based therapy had a chronic inflammatory disease, had an active malignancy, used steroids for a long period of time before 6 months, were using a medication that may influence energy homeostasis and had renal or liver dysfunction were excluded from the study.

Of the volunteers and the patients diagnosed with $\mathrm{CH}$ included in the study; 2 cc of blood were taken in a dry tube after obtaining informed consent. Bloods taken were centrifuged at a speed of 3,000 rpm for 15 minutes and the plasmas were stored at -80 degrees on the same day. In addition, patients' anthropometric and demographic characteristics, as well as history of drug use and smoking were also recorded. The volunteers included in the control group underwent $1 \mathrm{mg}$ DST screening test and CS was excluded.

UCP-1, irisin, PRDM-16 and BMP-7 were analyzed by using the brand elabscience commercial kits in the Radim Diagnostics Rome (Italy) device with Enzymelinked Immunosorbent Assay method in Kocaeli University Faculty of Medicine Biochemistry Research Laboratory. The unit was determined to be $\mathrm{ng} / \mathrm{mL}$.

\section{Statistical Analysis}

Statistical evaluation was performed by using the IBM SPSS 20.0 (IBM Corp., Armonk, NY, USA) package program. Conformity to normal distribution was evaluated with Kolmogorov-Smirnov test. Numerical variables exhibiting normal distribution were given as mean \pm standard deviation and those not exhibiting normal distribution as median $\left(25^{\text {th }}-75^{\text {th }}\right.$ percentiles), whereas the categorical variables, however, were given as frequency (percentage). Intergroup difference was determined by using student t-test for numerical variables exhibiting normal distribution and using Mann-Whitney $U$ test for numerical variables not exhibiting normal distribution. Correlations between categorical variables were evaluated by using chi-squared analysis. For analysis of correlations between numerical variables, Spearman correlation analyses were used, as assumption of normal distribution could not be made. Considering the factors with an impact on the study, moderator analysis was used and the corrected values of the markers were interpreted again. For testing bidirectional hypotheses, a $p<0.05$ was considered sufficient for statistical significance.

\section{Results}

For the study, 48 patients diagnosed with $\mathrm{CH}$ (37 female, 11 male) and 40 volunteers (31 female, 9 male) as a control group were recruited. The mean age of the groups was similar. General characteristics and laboratory values of the patient and control groups are represented in Table 1.

When the markers for BAT were compared between the patient and control groups, the markers PRDM-16, irisin, BMP-7 and UCP-1 were determined to be similar between both groups (Table 2).

By using the moderator analysis in our analysis as weight and body mass index (BMI) were included as the factors influencing BAT, corrected values of markers of both groups were re-calculated in accordance with weight and $\mathrm{BMI}$ and then compared again, and the results were found to be similar between both groups $(p>0.05)$.

When the group with $\mathrm{CH}$ was evaluated in itself, it was determined that $19(40.4 \%)$ had a macroadenoma and $28(59.6 \%)$ a microadenoma. While $82 \%$ of patients underwent early remission, the disease persisted in $18 \%$ of patients. Furthermore, during their 6-year follow-up, $23 \%$ of the diagnosed patients were found to have a recurrence and $77 \%$ continued to be in remission.

Data on effects of the size adenomas, time to postoperative remission and rate of recurrence on markers for BAT are represented in Table 3.

A positive correlation was observed between preoperative basal cortisol and night-time cortisol 
and irisin, among the markers for BAT, and a negative correlation was observed between urinary free cortisol (UFC) and UCP-1 (Table 4).

By dividing the patient group as those with a $\mathrm{BMI}$ under 30 and over 30, irisin, PRDM-16, UCP-1 and BMP-7 were compared. BMP-7 was determined to be higher in the group with a BMI >30 $(p<0.05)$. No significant difference was detected for other markers for BAT $(p>0.05)$. In the comparison by triglyceride (TG) levels, PRDM-16 and BMP7 were determined to be higher in patients with a TG $<150$ ( $p<0.05$ ). No significant difference was determined between HbA1c and markers for BAT $(p>0.05)$.

\section{Discussion}

CS indicates pathological hypercortisolism as a result of excessive adrenocorticotropic hormone (ACTH)

\begin{tabular}{|c|c|c|c|}
\hline & Patient group & Control group & $\mathbf{p}$ \\
\hline Female $(n)(\%)$ & $37(77.1 \%)$ & $31(77.5 \%)$ & $>0.05$ \\
\hline Male (n) (\%) & $11(22.9 \%)$ & $9(22.5 \%)$ & $>0.05$ \\
\hline Age (years) (mean \pm SD) & $44.04 \pm 13.79$ & $45.30 \pm 9.31$ & $>0.05$ \\
\hline Weight $(\mathrm{kg})($ mean $\pm \mathrm{SD})$ & $82.47 \pm 13.13$ & $89.51 \pm 11.26$ & $<0.05$ \\
\hline $\mathrm{BMI}\left(\mathrm{kg} / \mathrm{m}^{2}\right)($ mean $\pm \mathrm{SD})$ & $31.29 \pm 5.76$ & $32.4 \pm 3.11$ & $<0.05$ \\
\hline $\mathrm{HbA} 1 \mathrm{c}(\%)$ & $6.3(5.7-6.8)$ & $5.6(5.3-5.9)$ & $<0.05$ \\
\hline CRP $(\mathrm{mg} / \mathrm{L})$ & $0.73(0.4-1.2)$ & $0.53(0.3-0.9)$ & $>0.05$ \\
\hline Triglyceride $(\mathrm{mg} / \mathrm{dL})($ mean $\pm \mathrm{SD})$ & $190.5 \pm 80$ & $83.5 \pm 49.2$ & $<0.05$ \\
\hline $\mathrm{HDL}(\mathrm{mg} / \mathrm{dL})($ mean $\pm \mathrm{SD})$ & $48.5 \pm 15.5$ & $51.3 \pm 10.7$ & $>0.05$ \\
\hline $\mathrm{LDL}(\mathrm{mg} / \mathrm{dL})($ mean $\pm \mathrm{SD})$ & $125.1 \pm 27.5$ & $134.6 \pm 27.9$ & $>0.05$ \\
\hline $25-\mathrm{OH}(\mathrm{mg} / \mathrm{mL})($ mean $\pm \mathrm{SD})$ & $15.3 \pm 7.83$ & $17.9 \pm 8.31$ & $>0.05$ \\
\hline
\end{tabular}

Table 2. Comparison of the patient and control groups for markers for BAT

\begin{tabular}{|l|l|l|l|}
\hline & Patient group & Control group & $\mathbf{p}$ \\
\hline UCP-1 $(\mathrm{ng} / \mathrm{mL})$ & $1.4 \pm 1.09$ & $1.3 \pm 0.74$ & $>0.05$ \\
\hline İisin $(\mathrm{ng} / \mathrm{mL})$ & $3.2 \pm 0.8$ & $2.7 \pm 1.16$ & $>0.05$ \\
\hline BMP-7 $(\mathrm{ng} / \mathrm{mL})$ & $148.1 \pm 97.9$ & $158.8 \pm 84.78$ & $>0.05$ \\
\hline PRDM-16 $(\mathrm{ng} / \mathrm{mL})$ & $207.6 \pm 136.3$ & $306.9 \pm 308.6$ & $>0.05$ \\
\hline UCP-1: Uncoupling protein-1, BMP-7: Bone morphogenetic protein-7, PRDM-16: PR-Domain Zinc Finger Protein-16, BAT: Brown adipose tissue
\end{tabular}

\begin{tabular}{|c|c|c|c|c|c|c|}
\hline & Recurred & Not recurred & $\begin{array}{l}\text { Those with early } \\
\text { remission }\end{array}$ & $\begin{array}{l}\text { Those without } \\
\text { early remission }\end{array}$ & Microadenoma & Macroadenoma \\
\hline İrisin (25\%-75\%) & $\begin{array}{l}3.6 \\
(3.1-3.7)\end{array}$ & \begin{tabular}{|l|}
3.7 \\
$(2.2-3.7)$
\end{tabular} & \begin{tabular}{|l|}
3.7 \\
$(2.6-3.7)$
\end{tabular} & \begin{tabular}{|l|}
3.7 \\
$(3.7-3.7)$
\end{tabular} & $\begin{array}{l}3.7 \\
(2.29-3.7)\end{array}$ & \begin{tabular}{|l}
3.7 \\
$(3.5-3.7)$
\end{tabular} \\
\hline$p$ & \multicolumn{2}{|l|}{$>0.05$} & \multicolumn{2}{|l|}{$>0.05$} & \multicolumn{2}{|l|}{$>0.05$} \\
\hline UCP-1(25\%-75\%) & $\begin{array}{l}0.79 \\
(0.43-1.12) \\
\end{array}$ & \begin{tabular}{|l|}
0.91 \\
$(0.56-2.43)$
\end{tabular} & $\begin{array}{l}1.12 \\
(0.55-2.36)\end{array}$ & \begin{tabular}{|l|}
2.5 \\
$(0.5-2.7)$
\end{tabular} & $\begin{array}{l}1.68 \\
(0.61-2.6)\end{array}$ & $\begin{array}{l}1.01 \\
(0.49-1.27)\end{array}$ \\
\hline$p$ & \multicolumn{2}{|l|}{$>0.05$} & \multicolumn{2}{|l|}{$>0.05$} & \multicolumn{2}{|l|}{$<0.05$} \\
\hline PRDM-16 (25\%-75\%) & $\begin{array}{l}180 \\
(146-263)\end{array}$ & $\begin{array}{l}153 \\
(138-217)\end{array}$ & $\begin{array}{l}157 \\
(142-281)\end{array}$ & $\begin{array}{l}164 \\
(132-195)\end{array}$ & $\begin{array}{l}160 \\
(140-240)\end{array}$ & $\begin{array}{l}152 \\
(138-197)\end{array}$ \\
\hline$p$ & \multicolumn{2}{|l|}{$>0.05$} & \multicolumn{2}{|l|}{$>0.05$} & \multicolumn{2}{|l|}{$>0.05$} \\
\hline BMP-7 (25\%-75\%) & $\begin{array}{l}98.9 \\
(60-135)\end{array}$ & \begin{tabular}{|l}
104 \\
$(67-240)$
\end{tabular} & $\begin{array}{l}127 \\
(72-210)\end{array}$ & \begin{tabular}{|l|}
217 \\
$(77-350)$
\end{tabular} & $\begin{array}{l}157 \\
(67-242)\end{array}$ & \begin{tabular}{|l|}
86 \\
$(65-177)$
\end{tabular} \\
\hline$p$ & \multicolumn{2}{|l|}{$>0.05$} & \multicolumn{2}{|l|}{$>0.05$} & \multicolumn{2}{|l|}{$>0.05$} \\
\hline
\end{tabular}


Selek et al. Glucocorticoid and Brown Fat Tissue

Table 4. Correlation analysis of markers for BAT and hormones in the patient group

\begin{tabular}{|c|c|c|c|c|c|c|c|c|}
\hline & \multicolumn{2}{|c|}{ Basal ACTH } & \multicolumn{2}{|c|}{ Basal cortisol } & \multicolumn{2}{|c|}{ Night-time cortisol } & \multicolumn{2}{|c|}{ Urinary free cortisol } \\
\hline & $r$ & $p$ & $r$ & $p$ & $r$ & $p$ & $r$ & $p$ \\
\hline irisin & 0.041 & 0.783 & 0.328 & 0.024 & 0.375 & 0.019 & 0.143 & 0.411 \\
\hline UCP-1 & -0.09 & 0.546 & 0.145 & 0.331 & -0.079 & 0.633 & -0.391 & 0.020 \\
\hline PRDM-16 & -0.124 & 0.405 & -0.097 & 0.518 & 0.155 & 0.346 & -0.004 & 0.984 \\
\hline BMP-7 & -0.164 & 0.272 & 0.094 & 0.528 & -0.082 & 0.621 & -0.239 & 0.167 \\
\hline
\end{tabular}

production or autonomous adrenal cortisol production. Adrenocorticotropic hormone -dependent cortisol excess due to a pituitary adenoma is called $\mathrm{CH}$ and it accounts for $80 \%$ of endogenous CS. CS is associated with hypertension, diabetes, coagulopathy, cardiovascular diseases, infections and fractures, all of which may lead to significant morbidity and mortality (9).

Glucocorticoids are an important part of human and animal physiology as a modulator of inflammation and glucose homeostasis, mainly during the stress response. Furthermore, glucocorticoids have been found to play a significant role in energy homeostasis and physiology of adipose tissue over the years (10). Abnormal levels of circulating glucocorticoids directly affect the physiology of WAT at both cellular and molecular level, stimulating adipogenesis and leading to enlargement of adipose tissue (11). Observed importance of the need for glucocorticoids for WAT function has led to foresight that glucocorticoids may also modulating BAT function. In fact, BAT has also been shown to be a target organ for glucocorticoids in early studies (12). Similar to effect on WAT, glucocorticoids may induce lipid deposition in BAT and this may reflect an impaired UCP-1-related thermogenic capacity. If excessive exposure to glucocorticoids suppresses BAT thermogenesis, this may reduce dietary thermogenic energy expenditure and it has been suggested that this may contribute to the development of glucocorticoidsinduced obesity in mice and humans (13).

In this study, it was aimed to demonstrate alterations in UCP-1, irisin, PRDM-16 and BMP-7, which are considered to be markers for BAT, in $\mathrm{CH}$ that is a hypercortisolemic condition compared to healthy volunteers, under the light of the data obtained from in vivo and in vitro studies.

Activity of the hypothalamic-pituitary-adrenal axis has an impact on production and secretion of glucocorticoids. Glucocorticoids may modulate UCP-1-induced thermogenesis in BAT. High levels of ACTH appear to up-regulate UCP1 transcription in vitro. Accordingly, an increase in UCP1 mRNA and UCP-1 protein levels after treatment with ACTH was determined in studies on cultured adipocytes $(14,15)$. ACTH-induced up-regulation of UCP-1 levels most likely occurs via activation of Gs-cAMP-protein kinase A
(PKA) signaling following binding of $\mathrm{ACTH}$ to the cognate melanocortin 2 receptor (16). When exposed to a stress factor, while circulating glucocorticoids levels increase after 20 minutes, circulating ACTH levels increase much more rapidly. Therefore, ACTH may initially promote the activity of BAT, and this effect may then be suppressed with an increase in glucocorticoids. However, ACTH concentrations used in animal studies are at least 5-fold higher than the maximal physiological ACTH concentration in case of stress $(15,17,18)$. Because effects of ACTH on BAT are dose-dependent and they occur at these supraphysiological doses, it is unlikely for ACTH-induced activation of UCP-1-induced thermogenesis to be related under physiological conditions (19). In our research, serum basal ACTH levels were found to have no effect on BAT. This, in turn, supports the idea in the literature that exposure to ACTH at physiological doses has no significant effect on BAT.

First clues for a potential association between glucocorticoids and BAT function were obtained from studies on adrenalectomized rats. The researchers observed that there was a significant reduction in lipid stores in BAT in adrenalectomized rats and mice as earlier as 1949 (20). In such adrenalectomized rodents, regaining of lipid stores after glucocorticoid injection indicates that the effect of adrenalectomy on BAT actually results from absence of glucocorticoids (21). Based upon this, in earlier studies, the hypothesis that adrenalectomy inhibits glucocorticoidsinduced suppression of BAT thermogenesis and, thusly, increases energy expenditure and reduces the incidence of obesity was proposed (22). Therefore, consistent with this, BAT function may be clearly suppressed in presence of glucocorticoids. In animal studies, chronic glucocorticoid treatment has been reported to cause deep lipid deposition in BAT and a reduction in UCP-1 mRNA and UCP-1 protein levels $(8,14)$. However, there also are studies which did not found any alteration in BAT UCP-1 protein levels or UCP-1induced thermogenic capacity (23). Direct human studies on effects of glucocorticoids on BAT are very limited due to challenges in sample tissue collection. Nevertheless, there are indicators demonstrating a suppressive effect of glucocorticoids on BAT in humans. In retroperitoneal 
adipose tissue analysis of 57 patients, the intensity of BAT in patient groups with cortisol-secreting adenomas and secondary hypercortisolism was found to be lower compared to those with aldosterone-secreting adenomas, pheochromocytomas and nonfunctional adenomas (24). Again in this study, a negative correlation was also determined between UFC level and retroperitoneal UCP1 expression. Similarly, a negative correlation was also determined between the group with UFC and UCP-1 in the group with $\mathrm{CH}$ in our study.

The intensity of BAT is reduced in individuals on chronic glucocorticoids compared to matched controls (25). In a study by which effects of glucocorticoids on human BAT in vitro, UCP-1 levels were found to be up-regulated in presence of $10 \mu \mathrm{M}$ dexamethasone in supraclavicular human brown adipocyte cultures that differentiated for 9 days (7). However, the duration of exposure to glucocorticoids influences in vitro experimental results. For instance, while a 24-hour treatment with $100 \mathrm{nM}$ cortisol increases basal UCP-1 expression in human adipocytes, a 48-hour treatment with the same dose of cortisol does not do so. Furthermore, while a 24-hour treatment with $1 \mu \mathrm{M}$ cortisol does not influence UCP-1 gene expression, a 48-hour treatment with $1 \mu \mathrm{M}$ reduces basal UCP-1 mRNA levels (25). In our study, no difference in markers for BAT was determined between those with $\mathrm{CH}$ and healthy volunteers. UCP-1 and BMP-7 were increased in correlation with cortisol in $\mathrm{CH}$ patients. The reason for this may be interpreted as that long-lasting exposure to high-dose glucocorticoids leads to loss of functioning of adipose tissue in $\mathrm{CH}$ patients and to high levels of markers by causing an in vivo resistance.

İrisin, a thermogenic adipomyokine cleaved from Fibronectin type III domain-containing protein 5, plays a role in browning of the adipose tissue. Irisin facilitates glucose uptake by skeletal muscles, improves hepatic glucose and lipid metabolisms and has a positive effect on hyperlipidemia and hyperglycemia caused by obesity and metabolic syndrome, thereby acting as an insulinsensitizing hormone (26). In a study where irisin levels were examined in 40 BAT-positive and 40 BAT-negative women determined by using 18F-florodeoxyglucose positron emission tomography, no difference was observed between the groups (27). In a study on those with $\mathrm{CH}$, circulating irisin levels were determined to be lower compared to controlled $\mathrm{CH}$ group (in postoperative $1^{\text {st }}$ year) and the control group (28). In our study, no significant difference in irisin levels was found between the patient and control groups ( $p>0.05$ ).

Targeting brown fat in order to increase energy expenditure and promote negative energy balance has been a strategy being sought for a long period of time for the prevention and treatment of obesity (29). In previous studies, UCP-1 deficient mice exhibited increased an increasing susceptibility to diet-induced obesity (30). In a study conducted with obese individuals, PRDM-16 gene polymorphism was observed to be a risk factor for obesity (31). BMP-7, a member of transforming growth factor- $\beta$ superfamily is known for with its osteogenic properties and plays a role induction, development and regulation of adipocytes, especially BAT (32). In our study, the patient and control groups were similar in terms of weight and BMI. In the patient group, BMP-7 was found to be higher in patients with a BMl $<30 \mathrm{~kg} / \mathrm{m}^{2}$ compared to those with a $\mathrm{BMI}>30 \mathrm{~kg} / \mathrm{m}^{2}(\mathrm{p}<0.05)$. This is thought to be associated with mechanisms of resistance due to chronic glucocorticoid exposure.

\section{Study Limitations}

One of them is conduction of the study with a relatively small sample size. In addition, $\mathrm{CH}$ is usually latediagnosed unless it has an aggressive course and how long the patients are exposed to increased endogenous glucocorticoid levels cannot be clearly estimated.

\section{Conclusion}

Studies on the association between glucocorticoids and BAT function have been carried on for years. Data obtained from animal studies have developed an interest in the physiology of BAT in humans. However, due to technical challenges, data from human studies are limited. In this study, we aimed to evaluate the association between $\mathrm{CH}$ and BAT via irisin, UCP-1, PRDM-16 and BMP7. In $\mathrm{CH}$, results similar to those in healthy volunteers were obtained. A positive correlation was observed between serum cortisol and irisin, whereas a negative correlation was observed between urinary cortisol and UCP-1. Studies with larger groups will provide obtaining clear data on BAT function in $\mathrm{CH}$.

\section{Authorship Contributions}

Concept: A.S., I.T., B.C., Design: A.S., I.T., B.C., Data Collection or Processing: B.F.C., D.K., E.G., Analysis or Interpretation: A.S., M.S., Z.C., Literature Search: B.F.C., M.S., Writing: A.S., M.S., B.F.C.

Conflict of Interest: No conflict of interest was declared by the authors.

Financial Disclosure: This work was supported by Kocaeli University Scientific Research Projects Coordination Unit (2018/067HD).

\section{References}

1. Lacroix A, Feelders RA, Stratakis CA, Nieman LK. Cushing's syndrome. Lancet 2015;386:913-27. 
2. Lee $P$, Swarbrick MM, Ho KK. Brown adipose tissue in adult humans: a metabolic renaissance. Endocr Rev 2013;34:41338.

3. Carpentier AC, Blondin DP, Virtanen KA, Richard D, Haman F, Turcotte ÉE. Brown Adipose Tissue Energy Metabolism in Humans. Front Endocrinol (Lausanne) 2018;9:447.

4. Zhang $Y$, Xie $C$, Wang $H$, et al. Irisin exerts dual effects on browning and adipogenesis of human white adipocytes. Am J Physiol Endocrinol Metab 2016;311:530-41.

5. Tseng YH, Kokkotou E, Schulz TJ, et al. New role of bone morphogenetic protein 7 in brown adipogenesis and energy expenditure. Nature 2008;454:1000-4.

6. Harms M, Seale P. Brown and beige fat: development, function and therapeutic potential. Nat Med 2013;19:1252-63.

7. Barclay JL, Agada H, Jang C, Ward M, Wetzig N, Ho KK. Effects of glucocorticoids on human brown adipocytes. J Endocrinol 2015;224:139-47.

8. Strack AM, Bradbury MJ, Dallman MF. Corticosterone decreases nonshivering thermogenesis and increases lipid storage in brown adipose tissue. Am J Physiol 1995;268:18391.

9. Nieman LK, Biller BM, Findling JW, et al. Treatment of Cushing's Syndrome: An Endocrine Society Clinical Practice Guideline. J Clin Endocrinol Metab 2015;100:2807-31.

10. Rockall AG, Sohaib SA, Evans D, et al. Computed tomography assessment of fat distribution in male and female patients with Cushing's syndrome. Eur J Endocrinol 2003;149:561-7.

11. Infante M, Armani A, Mammi C, Fabbri A, Caprio M. Impact of Adrenal Steroids on Regulation of Adipose Tissue. Compr Physiol 2017;7:1425-47.

12. Feldman D. Evidence that brown adipose tissue is a glucocorticoid target organ. Endocrinology 1978;103:2091-7.

13. Mousovich-Neto F, Matos MS, Costa ACR, et al. Brown adipose tissue remodelling induced by corticosterone in male Wistar rats. Exp Physiol 2019;104:514-28.

14. van den Beukel JC, Grefhorst A, et al. Direct activating effects of adrenocorticotropic hormone (ACTH) on brown adipose tissue are attenuated by corticosterone. FASEB J 2014;28:4857-67.

15. Biswas HM. Effect of adrenocorticotropic hormone on UCP1 gene expression in brown adipocytes. J Basic Clin Physiol Pharmacol 2017;28:267-74.

16. Schnabl K, Westermeier J, Li Y, Klingenspor M. Opposing Actions of Adrenocorticotropic Hormone and Glucocorticoids on UCP1-Mediated Respiration in Brown Adipocytes. Front Physiol 2019;9:1931.

17. Iwen KA, Senyaman O, Schwartz A, et al. Melanocortin crosstalk with adipose functions: ACTH directly induces insulin resistance, promotes a pro-inflammatory adipokine profile and stimulates UCP-1 in adipocytes. J Endocrinol 2008; 196:465-72.
18. Rothwell NJ, Stock MJ. Acute and chronic effects of ACTH on thermogenesis and brown adipose tissue in the rat. Comp Biochem Physiol A Comp Physiol 1985;81:99-102.

19. Luijten IHN, Cannon B, Nedergaard J. Glucocorticoids and Brown Adipose Tissue: Do glucocorticoids really inhibit thermogenesis? Mol Aspects Med 2019;68:42-59.

20. FAWCETT DW, JONES IC. The effects of hypophysectomy, adrenalectomy and of thiouracil feeding on the cytology of brown adipose tissue. Endocrinology 1949;45:609-21.

21. LACHANCE J, PAGE E. Hormonal factors influencing fat deposition in the interscapular brown adipose tissue of the white rat. Endocrinology 1953;52:57-64.

22. Yukimura $Y$, Bray GA, Wolfsen AR. Some effects of adrenalectomy in the fatty rat. Endocrinology 1978;103:19248.

23. Luijten IHN, Brooks K, Boulet $N$, et al. GlucocorticoidInduced Obesity Develops Independently of UCP1. Cell Rep 2019;27:1686-98.

24. Betz MJ, Slawik M, Lidell ME, et al. Presence of brown adipocytes in retroperitoneal fat from patients with benign adrenal tumors: relationship with outdoor temperature. J Clin Endocrinol Metab 2013;98:4097-104.

25. Ramage LE, Akyol M, Fletcher AM, et al. Glucocorticoids Acutely Increase Brown Adipose Tissue Activity in Humans, Revealing Species-Specific Differences in UCP-1 Regulation. Cell Metab 2016;24:130-41.

26. Chen N, Li Q, Liu J, Jia S. Irisin, an exercise-induced myokine as a metabolic regulator: an updated narrative review. Diabetes Metab Res Rev 2016;32:51-9.

27. Choi HY, Kim S, Park JW, et al. Implication of circulating irisin levels with brown adipose tissue and sarcopenia in humans. J Clin Endocrinol Metab 2014;99:2778-85.

28. Guarnotta V, Prinzi A, Pitrone M, Pizzolanti G, Giordano C. Circulating Irisin Levels as a Marker of OsteosarcopenicObesity in Cushing's Disease. Diabetes Metab Syndr Obes 2020;13:1565-74.

29. Tseng YH, Cypess AM, Kahn CR. Cellular bioenergetics as a target for obesity therapy. Nat Rev Drug Discov 2010;9:46582.

30. Kontani Y, Wang Y, Kimura K, et al. UCP1 deficiency increases susceptibility to diet-induced obesity with age. Aging Cell 2005;4:147-55.

31. Al Amrani A, AbdelKarim M, AlZoghaibi M. PRDM16 Gene Polymorphism Is Associated with Obesity and Blood Lipids Profiles in Saudi Population. J Clin Med 2018;7:141.

32. Zamani N, Brown CW. Emerging roles for the transforming growth factor-\{beta\} superfamily in regulating adiposity and energy expenditure. Endocr Rev 2011;32:387-403. 